\title{
PROGRAMAS DE SECAGEM PARA MARUPÁ (Simarouba amara), PARÁ-PARÁ (Jacaranda copaia) E VIROLA (Virola surinamensis)
}

\author{
Jackson Roberto Eleotério ${ }^{1}$, Cláudia Mariana Kirchheim da Silva² \\ ${ }^{1}$ Eng. Florestal, Dr., Depto. de Engenharia Florestal, FURB, Blumenau, SC, Brasil - jreleote@furb.br \\ ${ }^{2}$ Eng $^{a}$. Florestal, PIBIC/FURB, Blumenau, SC, Brasil - silva.florestal@yahoo.com
}

Recebido para publicação: 10/12/2013 - Aceito para publicação: 26/11/2013

\begin{abstract}
Resumo
Um programa de secagem é uma indicação, para cada espécie e espessura, das condições ambientais necessárias dentro da câmara de secagem convencional, que equilibram as taxas de secagem com a formação de defeitos. Entre as metodologias para a elaboração de programas de secagem, destacam-se aquelas baseadas em equações empíricas cuja variável independente é a massa específica e aquelas baseadas na avaliação da secagem de pequenas amostras em condições drásticas, avaliando parâmetros como rachaduras, velocidades e taxas de secagem. O objetivo deste trabalho foi aplicar e comparar duas metodologias na elaboração de programas de secagem para marupá (Simarouba amara), pará-pará (Jacaranda copaia) e virola (Virola surinamensis). Os parâmetros para a elaboração dos programas de secagem foram obtidos experimentalmente em 32, 32 e 29 peças de marupá, pará-pará e virola, respectivamente. Comparando-se, por espécie, as temperaturas de secagem, verificou-se que, para marupá e virola, há diferenças estatísticas até o teor de umidade de $30 \%$, enquanto que para pará-pará o quadro foi inverso, apresentando valores significativamente similares até os $25 \%$ de umidade e diferentes no restante das fases. Com relação aos potenciais de secagem, os métodos resultaram em médias estatisticamente diferentes em todas as fases para todas as espécies analisadas.

Palavras-chave: Secagem convencional; madeiras tropicais; massa específica.
\end{abstract}

\begin{abstract}
Drying kiln schedules for marupá (Simarouba amara), pará-pará (Jacaranda copaia) and virola (Virola surinamensis). A drying kiln schedules is a prescript, for every each species and thickness, of environmental conditions inside drying chamber, which equilibrate the drying rates and formation defects. Among the methodologies of drying kiln schedules elaboration, those based on application of empiric equations having the specific gravity as independent variable and those based on evaluation of small pieces during drastic drying are highlighted. The objective of this research was to apply and to compare these two methodologies for drying kiln schedules elaboration for marupá, pará-pará and virola. The parameters for drying schedules elaboration were experimentally obtained on 32,32 and 29 pieces of marupá, pará-pará and virola, respectively. Comparing the drying potential obtained by different methods, it was different at all steps for all species, and the dry bulb temperature is different until the moisture content of 30\% for marupá and virola and under this point for pará-pará.

Keywords: Conventional drying; tropical woods; specific gravity.
\end{abstract}

\section{INTRODUÇÃO}

O teor de umidade da madeira, inicialmente elevado, é uma importante característica desse material biológico, higroscópico e anisotrópico. A secagem é a etapa necessária para reduzir a umidade para valores compatíveis com o uso que se dará a esse material, minimizando as variações dimensionais e $\mathrm{o}$ ataque por fungos xilófagos, além de interferir positivamente nas propriedades mecânicas e na resistência elétrica.

Os inúmeros métodos de secagem podem ser agrupados em convectivos, como secagem ao ar, secagem convencional e secagem por desumidificação, e não convectivos, como secagem a vácuo e secagem por alta frequência. Entre os métodos convectivos, destaca-se a secagem convencional, pois permite reduzir o tempo da secagem com maior controle sobre os defeitos, através de especificação dos 
parâmetros do processo, como temperatura, sentido do fluxo, velocidade e umidade relativa do ar. Entretanto, a fim de compatibilizar taxas de secagem com controle dos defeitos, faz-se necessária a adoção de programas de secagem adequados. Entre os fatores que influenciam nas taxas de secagem e na qualidade da madeira seca desejada, estão a massa específica, a espessura da peça, o teor de umidade inicial e o teor de umidade final esperados, a proporção de cerne e de alburno e a propensão à formação de defeitos, relacionados com as características químicas, anatômicas e com a retratibilidade de cada espécie. Um programa de secagem não é capaz de considerar todos esses aspectos, mas busca levar em conta os mais significativos na formação de defeitos e na taxa de secagem.

Entre os diversos métodos de elaboração de programas de secagem, destaca-se o método proposto por Simpson (1996), no qual a temperatura de bulbo seco e a depressão psicrométrica inicial são estimadas a partir da massa específica básica. As temperaturas de bulbo seco são mantidas constantes até que a madeira alcance $30 \%$ de umidade e em seguida são elevadas a uma taxa de $5,6{ }^{\circ} \mathrm{C}$ para cada $5 \%$ de redução no teor de umidade. A depressão psicrométrica é calculada em função da umidade da madeira e da depressão psicrométrica inicial. Mais detalhes podem ser obtidos em Simpson (1996).

Apesar de esse procedimento ter apresentado bons resultados para espécies com programas de secagem desconhecidos, o comportamento da madeira durante a secagem, especialmente a formação de defeitos, não é totalmente explicado pela relação com a massa específica, de modo que ele não é recomendado em casos em que existem outros parâmetros disponíveis (ANDRADE et al., 2001). Outro método, proposto por Simpson e Verrill (1997), segue a mesma linha metodológica de Simpson (1996), partindo da massa específica básica para a definição de códigos das tabelas de temperatura, depressão psicrométrica e umidade para a primeira mudança na depressão psicrométrica do Dry Kiln Operator's Manual. Entre as vantagens desses métodos, estão a simplicidade e a facilidade na utilização de uma única variável independente, a massa específica básica.

A avaliação de pequenas amostras durante a secagem drástica foi utilizada na metodologia para a elaboração de programas de secagem por Jankowsky (2009), Santos (2002) e Andrade (2000), entre outros. O método leva em consideração aspectos importantes e influentes na retirada de água da madeira, como os efeitos das características físicas da madeira, intensidade de defeitos e quantificação das taxas de secagem, possibilitando também o agrupamento entre diferentes espécies em um mesmo programa. No entanto, existem também alguns aspectos negativos, como a necessidade de medições periódicas, longo tempo de experimentação, variável de acordo com cada espécie e eventuais dificuldades operacionais, embora todo esse processo seja necessário para obter um programa de secagem adequado à madeira em questão (JANKOWSKY, 2009).

Dentre as espécies que compõem os mais de 200 milhões de hectares de florestas nativas de produção (ASSOCIAÇÃO BRASILEIRA DA INDÚSTRIA DE MADEIRA PROCESSADA MECANICAMENTE (ABIMCI), 2008), com potencial para a produção de produtos de maior valor agregado, como molduras, e que carecem de informações sobre a secagem convencional, se encontram o marupá (Simarouba amara Aubl.), o pará-pará (Jacaranda copaia (Aubl.) D. Don) e a virola (Virola surinamensis (Rol. ex Rottb.) Warb.).

Marupá (Simarouba amara), também conhecida como caixeta, paraparaíba e marupaúba, entre outros nomes, está presente em diversas regiões da Amazônia e nos estados da Bahia, Ceará e Pernambuco. Apresenta cerne e alburno indistintos, pela cor branco-palha levemente amarelada; grã direita, com textura média e brilho moderado; cheiro imperceptível e gosto levemente amargo; resistência ao corte baixa, com durabilidade boa quando seca; e massa específica básica na ordem de $370 \mathrm{~kg} / \mathrm{m}^{3}$ (MARQUES et al., 1997), sendo considerada uma madeira leve.

Pará-pará (Jacaranda copaia) possui ampla distribuição na região amazônica, sendo muito utilizada para fins de carpintaria, compensados, caixas e laminados. A massa específica básica é de $310 \mathrm{~kg} / \mathrm{m}^{3}$ (INSTITUTO BRASILEIRO DO MEIO AMBIENTE E DOS RECURSOS NATURAIS RENOVÁVEIS (IBAMA), 2011), sendo considerada uma madeira de baixa densidade. Apresenta cerne e alburno indistintos, pela cor branco a branco-amarelado; grã direita, textura média, brilho moderado e cheiro imperceptível. É vulnerável ao ataque de organismos xilófagos.

Virola (Virola surinamensis), também conhecida como ucuúba, ocorre nos estados brasileiros do Amapá, Amazonas, Maranhão, Pará, Pernambuco e Roraima. Apresenta como características gerais cerne e alburno indistintos; cor marrom-muito-pálido; camadas de crescimento distintas; grã direita; textura fina 
a média; brilho moderado; cheiro imperceptível, com resistência ao corte manual macia. Possui massa específica básica em média de $350 \mathrm{~kg} / \mathrm{m}^{3}$, sendo caracterizada como leve (IBAMA, 2011).

Apesar de a madeira das três espécies consideradas neste trabalho apresentarem massa específica básica semelhantes e serem classificadas como madeiras leves, acredita-se que a secagem drástica, por levar em consideração diversos aspectos envolvidos na secagem, como rachaduras e taxas de secagem, possa apresentar programas de secagem diferentes dos obtidos por meio da massa específica básica.

Portanto, o objetivo deste trabalho foi comparar, para madeira de marupá, pará-pará e virola, programas de secagem elaborados a partir da massa específica com programas de secagem elaborados a partir da secagem drástica.

\section{MATERIAL E MÉTODOS}

\section{Elaboração de programas de secagem a partir da secagem drástica}

$\mathrm{O}$ método da secagem drástica se baseia no princípio de que pequenas amostras de madeira, quando expostas aos efeitos de secagem drástica em estufa a $100{ }^{\circ} \mathrm{C}$, apresentam um comportamento proporcional ao observado na secagem convencional. $\mathrm{O}$ método foi baseado nas recomendações e metodologias apresentadas em Jankowsky (2009).

Para aplicação desse método, foram utilizadas 32, 32 e 29 amostras de marupá, pará-pará e virola, respectivamente, sendo que todas apresentavam dimensões nominais de $10 \mathrm{~mm}$ de espessura, $50 \mathrm{~mm}$ de largura e $100 \mathrm{~mm}$ de comprimento. As amostras das três espécies foram mantidas em estufa a $100{ }^{\circ} \mathrm{C}$ até alcançarem um teor de umidade inferior a 5\%. Durante esse período, os corpos de prova foram pesados com intervalos de 1 hora, e os defeitos, como comprimento e largura de rachaduras, foram medidos utilizando-se paquímetro e calibrador de folga. A magnitude das rachaduras foi transformada em escore de acordo com Jankowsky (2009).

Os parâmetros para a definição dos programas de secagem - temperatura inicial $\left(\mathrm{T}_{\mathrm{i}}\right)$, temperatura final $\left(\mathrm{T}_{\mathrm{f}}\right)$ e potencial de secagem (PS) - foram obtidos através das taxas e velocidades de secagem e dos escores obtidos através das dimensões dos defeitos. As equações 1 a 3, extraídas de Jankowsky (2009), estimam os parâmetros do programa de secagem em função das taxas, velocidades e escores obtidos na secagem drástica.

$$
\begin{aligned}
& \mathrm{T}_{\mathrm{i}}=27,9049+0,7881\left(\mathrm{~T}_{2}\right)+419,0254\left(\mathrm{~V}_{1}\right)+1,9483\left(\mathrm{R}_{2}\right) \\
& \mathrm{T}_{\mathrm{f}}=49,2292+1,1834\left(\mathrm{~T}_{2}\right)+273,8685\left(\mathrm{~V}_{2}\right)+1,0754\left(\mathrm{R}_{1}\right) \\
& \mathrm{PS}=1,4586-30,4418\left(\mathrm{~V}_{3}\right)+42,9653\left(\mathrm{~V}_{1}\right)+0,1424\left(\mathrm{R}_{3}\right)
\end{aligned}
$$

Sendo: $\mathrm{T}_{2}=$ tempo de secagem da umidade inicial até $30 \%(\mathrm{~h})$;

$\mathrm{V}_{1}=$ taxa de secagem da umidade inicial até $5 \%\left(\mathrm{~g} / \mathrm{cm}^{2} . \mathrm{h}\right)$

$\mathrm{V}_{2}=$ taxa de secagem da umidade inicial até $30 \%\left(\mathrm{~g} / \mathrm{cm}^{2} . \mathrm{h}\right)$

$\mathrm{V}_{3}=$ taxa de secagem de 30 a $5 \%$ de umidade $\left(\mathrm{g} / \mathrm{cm}^{2} . \mathrm{h}\right)$;

$\mathrm{R}_{1}=$ intensidade das rachaduras da umidade inicial até 5\%;

$\mathrm{R}_{2}=$ intensidade das rachaduras da umidade inicial até $30 \%$;

$\mathrm{R}_{3}=$ intensidade das rachaduras de $30 \%$ a $5 \%$.

A apresentação detalhada da metodologia é encontrada em Jankowsky (2009). Os parâmetros dos programas de secagem foram comparados entre espécies pelo teste de Tukey com $\alpha=5 \%$.

\section{Definição de programas de secagem em função da massa específica básica}

Para os programas de secagem elaborados segundo o método proposto por Simpson (1996), foi utilizada a massa específica básica determinada nos mesmos corpos de prova utilizados para a secagem drástica.

O método parte de dois parâmetros: temperatura inicial $\left(\mathrm{T}_{\mathrm{i}}\right)$ e depressão psicrométrica inicial $\left(\mathrm{D}_{\mathrm{i}}\right)$, determinados através das equações 4 e 5 , respectivamente.

$$
\mathrm{T}_{\mathrm{i}}=\left(0,0115+0,0167 \rho_{\text {bás }}\right)^{-1}
$$




$$
\mathrm{D}_{\mathrm{i}}=\left(0,0832+0,509 \rho_{\text {bás }}\right)^{-1}
$$

Sendo: $\rho_{\text {bás. }}=$ massa específica básica $\left(\mathrm{g} / \mathrm{cm}^{3}\right)$.

A apresentação detalhada da metodologia é encontrada em Simpson (1996).

\section{Comparação entre os programas de secagem}

A temperatura de bulbo seco e o potencial de secagem, em cada uma das fases, foram os parâmetros utilizados na comparação dos programas de secagem obtidos por diferentes metodologias. A comparação foi realizada aplicando o teste de Tukey a 5\% de probabilidade de erro. As umidades de equilíbrio, necessárias para determinação dos parâmetros dos programas de secagem, foram calculadas com as equações apresentadas por Forest Products Laboratory (1999), e os potenciais de secagem foram calculados com o teor de umidade do início da fase, representando o valor máximo em cada etapa.

Os programas de secagem elaborados através da secagem drástica e em função da massa específica foram ainda confrontados com aqueles citados em Jankowsky e Luiz (2006), Mendes et al. (1998), Simpson (1996), Jankowsky (2009) e Centre de Cooperation Internationale en Recherche Agronomique pour le Developpement (2011), entretanto sem aplicação de testes de comparação de médias, pois não são apresentadas informações sobre a variabilidade dos dados disponíveis nas fontes bibliográficas consultadas.

\section{RESULTADOS E DISCUSSÃO}

Na tabela 1, estão relacionados os valores médios obtidos da umidade inicial, massa específica básica e das variáveis obtidas na secagem drástica, que foram utilizadas para a determinação dos parâmetros dos programas de secagem, como temperatura inicial $\left(\mathrm{T}_{\mathrm{i}}\right)$, temperatura final $\left(\mathrm{T}_{\mathrm{f}}\right)$ e potencial de secagem (PS).

Tabela 1. Valores médios das variáveis utilizadas para elaboração dos programas de secagem. Table 1. Average values of variables used for the drying schedules elaboration.

\begin{tabular}{|c|c|c|c|c|c|c|c|c|c|}
\hline Espécie & Ui (\%) & $\begin{array}{c}\rho_{\text {bás }} \\
\left(\mathrm{g} / \mathbf{c m}^{3}\right)\end{array}$ & $\begin{array}{l}\mathbf{T}_{2} \\
\text { (h) }\end{array}$ & $\begin{array}{c}V_{1} \\
\left(\mathrm{~g} / \mathrm{cm}^{2} . \mathrm{h}\right)\end{array}$ & $\begin{array}{c}V_{2} \\
\left(\mathrm{~g} / \mathrm{cm}^{2} . h\right)\end{array}$ & $\begin{array}{c}V_{3} \\
\left(\mathrm{~g} / \mathrm{cm}^{2} . h\right)\end{array}$ & $\mathbf{R}_{1}$ & $\mathbf{R}_{\mathbf{2}}$ & $\mathbf{R}_{\mathbf{3}}$ \\
\hline Marupá & 169,88 & 0,35 & 3,69 & 0,057 & 0,084 & 0,021 & 3,8 & 2,8 & 3,6 \\
\hline Para-pará & 205,35 & 0,34 & 5,18 & 0,044 & 0,062 & 0,015 & 3,8 & 3,6 & 3,4 \\
\hline Virola & 189,85 & 0,35 & 3,83 & 0,058 & 0,078 & 0,022 & 2,4 & 2,4 & 1,7 \\
\hline
\end{tabular}

$\mathrm{U}_{\mathrm{i}}$ : umidade inicial; $\rho_{\text {bás}}$ : massa específica básica; $\mathrm{T}_{2}$ : tempo de secagem da umidade inicial até $30 \%$; $\mathrm{V}_{1}$ : taxa de secagem da umidade inicial até 5\%; $\mathrm{V}_{2}$ : taxa de secagem da umidade inicial até 30\%; $\mathrm{V}_{3}$ : taxa de secagem de 30 a $5 \%$ de umidade; $\mathrm{R}_{1}$ : intensidade das rachaduras da umidade inicial até $5 \% ; \mathrm{R}_{2}$ : intensidade das rachaduras da umidade inicial até $30 \%$; $\mathrm{R}_{3}$ : intensidade das rachaduras de $30 \%$ a $5 \%$ de umidade.

De acordo com a classificação adotada por Durlo (1991), a massa específica das três espécies permite enquadrá-las como madeiras leves. Em relação ao marupá, os valores apresentados pelo Instituto de Pesquisas Tecnológicas do Estado de São Paulo (IPT) (1989), de 0,370 g/ $\mathrm{cm}^{3} ;$ por Fedalto et al. (1989) e pelo IBAMA (2011), de $0,380 \mathrm{~g} / \mathrm{cm}^{3}$; e por Simpson (1996), de $0,326 \mathrm{~g} / \mathrm{cm}^{3}$, estão de acordo com o obtido neste trabalho.

A massa específica básica da madeira de pará-pará obtida neste trabalho também resultou em valor médio próximo aos apresentados na literatura, de $0,340 \mathrm{~g} / \mathrm{cm}^{3}$ por Simpson (1996) e de $0,310 \mathrm{~g} / \mathrm{cm}^{3}$ segundo o IBAMA (2011) e o IPT (1989).

Para virola, a massa específica média é similar à apresentada pelo IBAMA (2011), de $0,350 \mathrm{~g} / \mathrm{cm}^{3}$, e inferior às apresentadas por Jankowsky (2009), de $0,377 \mathrm{~g} / \mathrm{cm}^{3}$, e por Simpson (1996), de $0,399 \mathrm{~g} / \mathrm{cm}^{3}$.

A caracterização das condições iniciais das amostras confirma a relação inversa entre massa específica básica e teor de umidade inicial. Correlações significativas, de $-80,8 \%$, de $-82,3 \%$ e de $-91,6 \%$, foram obtidas entre essas variáveis para madeira de marupá, para-pará e virola, respectivamente. A relação exponencial negativa entre a massa específica básica e o teor de umidade inicial também foi apresentada por Simpson (1996). 
Os valores obtidos para virola foram maiores no tempo $\left(\mathrm{T}_{2}\right)$ e nas velocidades $\left(\mathrm{V}_{1}\right.$ e $\left.\mathrm{V}_{3}\right)$ que os apresentados por Jankowsky (2009). Entretanto, os valores apresentados na velocidade V3 foram muito similares. Com relação à medição das rachaduras de topo, os valores de R1 e R2 foram superiores aos encontrados em Jankowsky (2009), sendo que o parâmetro R3 se mostrou similar. Para as outras duas espécies não foram encontrados valores que permitissem a comparação com os obtidos neste trabalho.

A espécie virola foi quem apresentou a maior variabilidade entre as peças, com um coeficiente de variação de $12,42 \%$ e $8,27 \%$ para o teor de umidade e para a massa específica, respectivamente.

\section{Programas de secagem baseados na secagem drástica}

As variáveis apresentadas na tabela 1 foram utilizadas nas equações 1 a 3 para definir os parâmetros fundamentais dos programas de secagem baseados na secagem drástica, que são apresentados na tabela 2 .

Tabela 2. Temperatura inicial, temperatura final e potencial de secagem para a madeira de marupá, parápará e virola.

Table 2. Initial temperature, final temperature and the drying potential for marupá, pará-pará and virola lumber.

\begin{tabular}{lccc}
\hline Espécie & Temperatura inicial $\left({ }^{\circ} \mathbf{C}\right)$ & Temperatura final $\left({ }^{\circ} \mathbf{C}\right)$ & Potencial de secagem \\
\hline Marupá & $60,3 \mathrm{a}$ & $80,7 \mathrm{a}$ & $3,8 \mathrm{a}$ \\
Pará-pará & $57,4 \mathrm{a}$ & $76,5 \mathrm{~b}$ & $3,4 \mathrm{~b}$ \\
Virola & $59,9 \mathrm{a}$ & $77,7 \mathrm{ab}$ & $3,5 \mathrm{ab}$ \\
\hline
\end{tabular}

Médias na mesma coluna, seguidas por mesmas letras minúsculas, não diferem significativamente pelo teste de Tukey com $\alpha$ : $5 \%$.

Em relação à temperatura inicial, não foram encontradas diferenças significativas entre as espécies, sendo significativas somente as diferenças na temperatura final e no potencial de secagem. A madeira de virola ocupa uma posição intermediária nessas duas últimas variáveis, não diferindo das demais espécies analisadas neste trabalho. Dessa forma, podemos discernir dois grupos de secagem, um deles formado por marupá e virola e o outro por pará-pará e virola. Para o primeiro grupo, são recomendadas temperaturas e potenciais de secagem mais elevados que para o segundo grupo, sendo que as temperaturas ao longo dos programas variam desde $57,4^{\circ} \mathrm{C}$ até $80,7^{\circ} \mathrm{C}$.

Jankowsky e Luiz (2006) recomendam, para as três espécies, temperatura inicial e final e potencial de secagem inferiores às obtidas neste trabalho.

\section{Programas de secagem pela massa específica básica}

Os valores obtidos neste trabalho para a temperatura inicial de $57,6{ }^{\circ} \mathrm{C}, 58,2{ }^{\circ} \mathrm{C}$ e de $57,6{ }^{\circ} \mathrm{C}$ são similares aos apresentados por Simpson (1996), de $55{ }^{\circ} \mathrm{C}, 58{ }^{\circ} \mathrm{C}$ e $55^{\circ} \mathrm{C}$ para marupá, pará-pará e virola, respectivamente. Essa semelhança se repetiu para a depressão psicrométrica inicial, com valores obtidos neste trabalho de $3,8{ }^{\circ} \mathrm{C}, 3,9^{\circ} \mathrm{C}$ e $3,8{ }^{\circ} \mathrm{C}$, próximos aos valores apresentados por Simpson (1996), de $3,5^{\circ} \mathrm{C}, 3,9^{\circ} \mathrm{C}$ e $3,5^{\circ} \mathrm{C}$ para marupá, pará-pará e virola, respectivamente.

Ainda que o método utilizado para determinação dos programas de secagem seja o mesmo, as diferenças nos resultados são explicadas pelos diferentes valores nas massas específicas utilizadas.

\section{Comparação entre os métodos de determinação dos programas de secagem}

Os programas de secagem foram elaborados de acordo com as recomendações contidas em Jankowsky (2009) e Simpson (1996) e apresentados nas tabelas 3 a 5 na forma resumida.

Os métodos para determinação dos programas de secagem aplicados na madeira de marupá resultaram em diferenças significativas na temperatura de bulbo seco da condição inicial até $30 \%$ de umidade, como apresentado na tabela 3. Através do método proposto por Simpson (1996), foram obtidas temperaturas mais amenas. Nas fases finais da secagem não foram encontradas diferenças significativas.

Com relação ao potencial de secagem, os métodos diferiram significativamente em todas as fases, sendo que o método calculado a partir da massa específica básica apresenta valores superiores e ainda um acentuado aumento no potencial de secagem entre 30 e $20 \%$ de umidade, reduzindo-se posteriormente. Essa tendência é uma característica encontrada em programas de secagem determinados segundo a metodologia proposta por Simpson (1996) e pode ser visualizada na figura 1. 
Tabela 3. Programas de secagem para madeira de marupá.

Table 3. Dry kiln schedules for marupá lumber.

\begin{tabular}{lcccc}
\hline $\begin{array}{l}\text { Faixa de } \\
\text { umidade da } \\
\text { madeira }\end{array}$ & \multicolumn{2}{c}{$\begin{array}{c}\text { Determinação através da } \\
\text { secagem drástica }\end{array}$} & \multicolumn{2}{c}{$\begin{array}{c}\text { Determinação através da } \\
\text { massa específica básica }\end{array}$} \\
\cline { 2 - 5 } & $\begin{array}{c}\text { Temperatura de } \\
\text { bulbo seco }\left({ }^{\mathbf{O}} \mathbf{C}\right)\end{array}$ & $\begin{array}{c}\text { Potencial de } \\
\text { secagem (PS) }\end{array}$ & $\begin{array}{c}\text { Temperatura de } \\
\text { bulbo seco }\left({ }^{\circ} \mathbf{C}\right)\end{array}$ & $\begin{array}{c}\text { Potencial de } \\
\text { secagem (PS) }\end{array}$ \\
\hline Até 45 & $60 \mathrm{~A}$ & $>3,3 \mathrm{a}$ & $58 \mathrm{~B}$ & $>3,5 \mathrm{~b}$ \\
$45-40$ & $60 \mathrm{~A}$ & $3,4 \mathrm{a}$ & $58 \mathrm{~B}$ & $3,5 \mathrm{~b}$ \\
$40-35$ & $60 \mathrm{~A}$ & $3,5 \mathrm{a}$ & $58 \mathrm{~B}$ & $3,8 \mathrm{~b}$ \\
$35-30$ & $60 \mathrm{~A}$ & $3,7 \mathrm{a}$ & $58 \mathrm{~B}$ & $4,2 \mathrm{~b}$ \\
$30-25$ & $65 \mathrm{~A}$ & $3,8 \mathrm{a}$ & $63 \mathrm{~A}$ & $5,9 \mathrm{~b}$ \\
$25-20$ & $71 \mathrm{~A}$ & $3,8 \mathrm{a}$ & $69 \mathrm{~A}$ & $5,8 \mathrm{~b}$ \\
$20-15$ & $76 \mathrm{~A}$ & $3,8 \mathrm{a}$ & $74 \mathrm{~A}$ & $4,2 \mathrm{~b}$ \\
$15-10$ & $81 \mathrm{~A}$ & $3,8 \mathrm{a}$ & $82 \mathrm{~A}$ & \\
\hline
\end{tabular}

Médias de TBS seguidas na linha por mesmas letras maiúsculas e médias de PS seguidas na linha por mesmas letras minúsculas não diferem significativamente pelo teste de Tukey com $\alpha$ : 5\%.
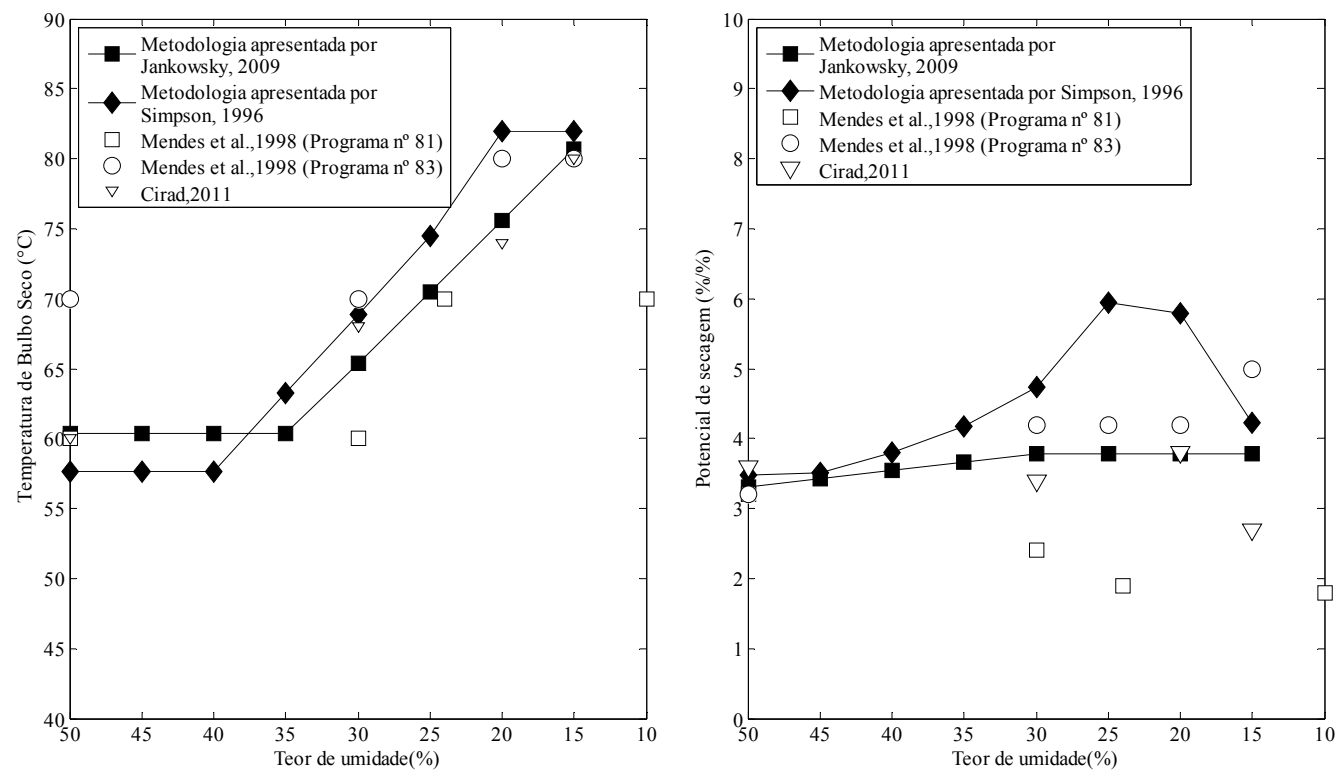

Figura 1. Temperatura de bulbo seco e do potencial de secagem em função da umidade da madeira para marupá.

Figure 1. Dry bulb temperature and drying potential as a function of marupá wood moisture content.

Na figura 1, observa-se que a temperatura de bulbo seco dos programas elaborados a partir da metodologia aplicada por Jankowsky (2009), o programa 81 de Mendes et al. (1998) e o apresentado por Cirad (2011) se mostraram semelhantes até alcançarem os $30 \%$ de umidade. O programa determinado a partir da massa específica, apesar de iniciar com temperaturas inferiores aos demais, apresentou-se mais severo na última faixa de umidade. As temperaturas iniciais recomendadas no programa 83, apresentado por Mendes et al. (1998), foram as que mais se diferenciaram das demais; contudo, ao final da secagem se aproximam das demais.

Os programas apresentados por Mendes et al. (1998), apesar de iniciarem com os mesmos valores de potencial de secagem, apresentam tendência de decréscimo ao longo da secagem, enquanto que os potenciais de secagem resultantes da secagem drástica se mantiveram constantes a partir de $30 \%$ de umidade (Figura 1). A metodologia utilizada por Simpson (1996) resultou em um potencial de secagem mais elevado que os demais, com uma tendência de diminuir no final do processo.

Com relação à temperatura de bulbo seco dos programas de secagem para madeira de pará-pará, os valores não diferiram significativamente até o teor de umidade de $25 \%$ (Tabela 4). Abaixo desse teor, 
os programas apresentam diferenças significativas, sendo que o programa elaborado a partir da massa específica resultou em temperatura mais alta que aquelas obtidas no programa elaborado através do método proposto por Jankowsky (2009).

Tabela 4. Programas de secagem para madeira de pará-pará.

Table 4. Dry kiln schedules for pará-pará lumber.

\begin{tabular}{lcccc}
\hline \multirow{2}{*}{$\begin{array}{l}\text { Faixa de } \\
\text { umidade da } \\
\text { madeira }\end{array}$} & \multicolumn{2}{c}{$\begin{array}{c}\text { Determinação através da } \\
\text { secagem drástica }\end{array}$} & \multicolumn{2}{c}{$\begin{array}{c}\text { Determinação através da } \\
\text { massa específica básica }\end{array}$} \\
\cline { 2 - 5 } & $\begin{array}{c}\text { Temperatura de } \\
\text { bulbo seco }\left(\mathbf{~}^{\circ} \mathbf{C}\right)\end{array}$ & $\begin{array}{c}\text { Potencial de } \\
\text { secagem }(\text { PS) }\end{array}$ & $\begin{array}{c}\text { Temperatura de } \\
\text { bulbo seco }\left({ }^{\circ} \mathbf{C}\right)\end{array}$ & $\begin{array}{c}\text { Potencial de } \\
\text { secagem (PS) }\end{array}$ \\
\hline tté 45 & $57 \mathrm{~A}$ & $>3,3 \mathrm{a}$ & $58 \mathrm{~A}$ & $>3,5 \mathrm{~b}$ \\
$45-40$ & $57 \mathrm{~A}$ & $3,3 \mathrm{a}$ & $58 \mathrm{~A}$ & $3,6 \mathrm{~b}$ \\
$40-35$ & $57 \mathrm{~A}$ & $3,3 \mathrm{a}$ & $58 \mathrm{~A}$ & $3,8 \mathrm{~b}$ \\
$35-30$ & $57 \mathrm{~A}$ & $3,4 \mathrm{a}$ & $58 \mathrm{~A}$ & $4,2 \mathrm{~b}$ \\
$30-25$ & $62 \mathrm{~A}$ & $3,4 \mathrm{a}$ & $64 \mathrm{~A}$ & $4,8 \mathrm{~b}$ \\
$25-20$ & $67 \mathrm{~A}$ & $3,4 \mathrm{a}$ & $69 \mathrm{~B}$ & $5,9 \mathrm{~b}$ \\
$20-15$ & $72 \mathrm{~A}$ & $3,4 \mathrm{a}$ & $75 \mathrm{~B}$ & $5,8 \mathrm{~b}$ \\
$15-10$ & $77 \mathrm{~A}$ & $3,4 \mathrm{a}$ & $82 \mathrm{~B}$ & $4,2 \mathrm{~b}$ \\
\hline
\end{tabular}

Médias de TBS seguidas na linha por mesmas letras maiúsculas e médias de PS seguidas na linha por mesmas letras minúsculas não diferem significativamente pelo teste de Tukey $\operatorname{com} \alpha: 5 \%$.

Com relação ao potencial de secagem, há diferença significativa em todas as fases, sendo inferiores os valores obtidos por meio da secagem drástica.

Com exceção do programa 81, apresentado por Mendes et al. (1998), nos programas de secagem recomendados para madeira de pará-pará as temperaturas de bulbo seco iniciais são inferiores às obtidas neste trabalho (Figura 2). Apesar de os programas elaborados a partir da secagem drástica e da massa específica iniciarem com temperaturas semelhantes, este último resultou em um programa com temperaturas finais mais elevadas.
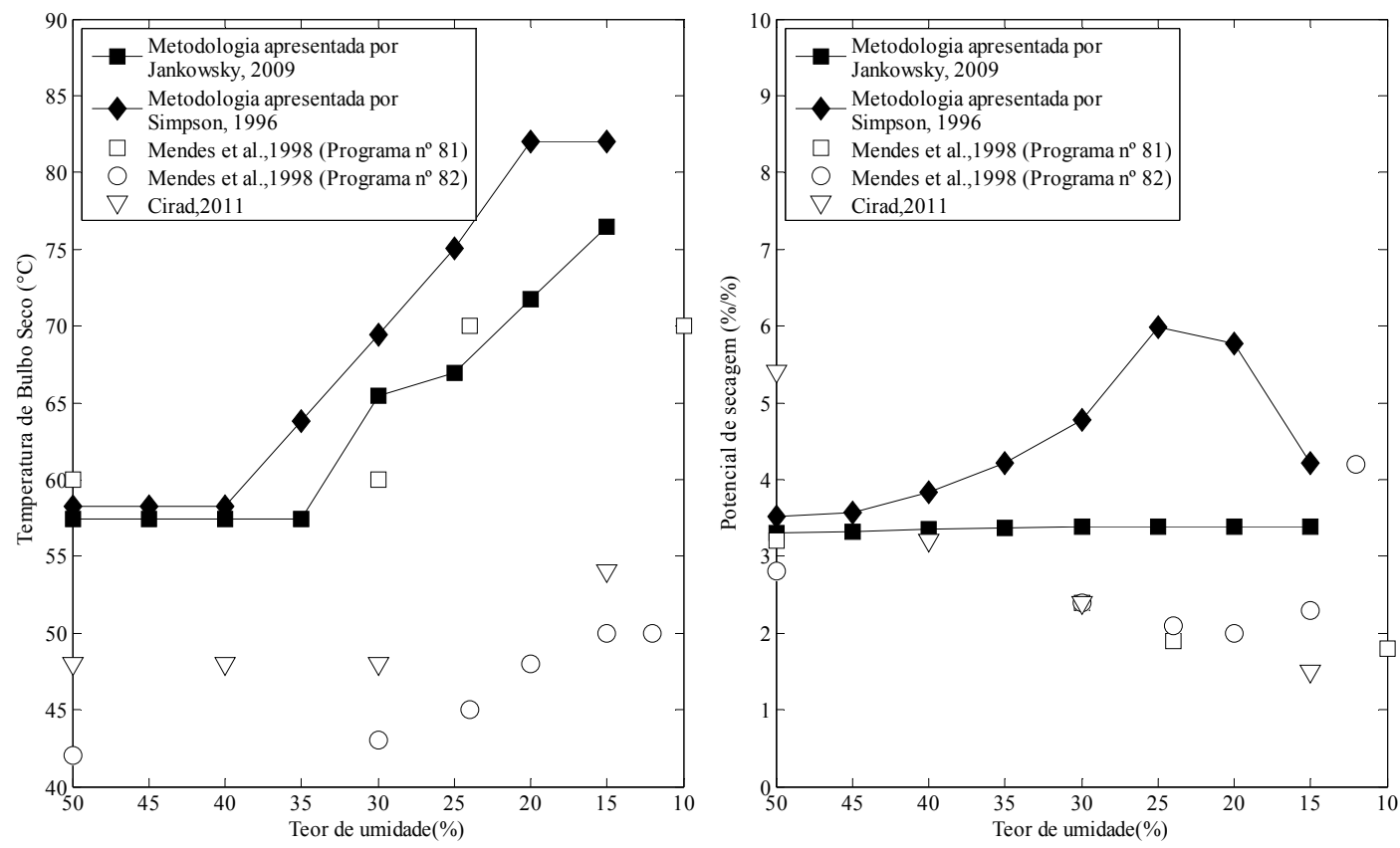

Figura 2. Temperatura de bulbo seco e do potencial de secagem em função da umidade da madeira para pará-pará.

Figure 2. Dry bulb temperature and drying potential as a function of pará-pará wood moisture content. 
Em relação ao potencial de secagem, o programa elaborado com a metodologia apresentada por Jankowsky (2009) se mantém praticamente constante ao longo da secagem, enquanto que os programas apresentados por Mendes et al. (1998) e Cirad (2011) decrescem em função da redução do teor de umidade. Os resultados obtidos a partir da massa específica básica seguiram a mesma tendência observada em marupá, de elevação acentuada logo abaixo do ponto de saturação das fibras.

Para virola, a temperatura de bulbo seco obtida pelos diferentes métodos apresentou diferença significativa até $30 \%$ de umidade, e entre 30 e $15 \%$ os valores não diferiram, o que voltou a ocorrer no final da secagem, abaixo de $15 \%$ de umidade (Tabela 5).

Tabela 5. Programas de secagem para madeira de virola.

Table 5. Dry kiln schedules for virola lumber.

\begin{tabular}{lcccc}
\hline \multirow{2}{*}{$\begin{array}{l}\text { Umidade da } \\
\text { madeira }\end{array}$} & \multicolumn{2}{c}{$\begin{array}{c}\text { Determinação através da } \\
\text { secagem drástica }\end{array}$} & \multicolumn{2}{c}{$\begin{array}{c}\text { Determinação através da } \\
\text { massa específica básica }\end{array}$} \\
\cline { 2 - 5 } & $\begin{array}{c}\text { Temperatura de } \\
\text { bulbo seco }\end{array}$ & $\begin{array}{c}\text { Potencial de } \\
\text { secagem }\end{array}$ & $\begin{array}{c}\text { Temperatura de } \\
\text { bulbo seco }\end{array}$ & $\begin{array}{c}\text { Potencial de } \\
\text { secagem }\end{array}$ \\
\hline Até 45 & $60 \mathrm{~A}$ & $>3,3 \mathrm{a}$ & $58 \mathrm{~B}$ & $>3,5 \mathrm{~b}$ \\
$45-40$ & $60 \mathrm{~A}$ & $3,4 \mathrm{a}$ & $58 \mathrm{~B}$ & $3,5 \mathrm{~b}$ \\
$40-35$ & $60 \mathrm{~A}$ & $3,4 \mathrm{a}$ & $58 \mathrm{~B}$ & $3,8 \mathrm{~b}$ \\
$35-30$ & $60 \mathrm{~A}$ & $3,5 \mathrm{a}$ & $58 \mathrm{~B}$ & $4,2 \mathrm{~b}$ \\
$30-25$ & $64 \mathrm{~A}$ & $3,5 \mathrm{a}$ & $63 \mathrm{~A}$ & $4,7 \mathrm{~b}$ \\
$25-20$ & $69 \mathrm{~A}$ & $3,5 \mathrm{a}$ & $69 \mathrm{~A}$ & $5,9 \mathrm{~b}$ \\
$20-15$ & $73 \mathrm{~A}$ & $3,5 \mathrm{a}$ & $74 \mathrm{~A}$ & $5,8 \mathrm{~b}$ \\
$15-10$ & $78 \mathrm{~A}$ & $3,5 \mathrm{a}$ & $82 \mathrm{~B}$ & $4,2 \mathrm{~b}$ \\
\hline
\end{tabular}

Médias de TBS seguidas na linha por mesmas letras maiúsculas e médias de PS seguidas na linha por mesmas letras minúsculas não diferem significativamente pelo teste de Tukey $\operatorname{com} \alpha: 5 \%$.

Com relação ao potencial de secagem, há diferença entre os métodos propostos em todas as fases do processo de secagem. A mesma tendência observada para as outras espécies, de potenciais aproximadamente constantes para o programa baseado na secagem drástica e de valores elevados entre 25 e $20 \%$ de umidade para o programa de secagem baseado na massa específica, foi encontrado em virola, como pode ser visualizado na figura 3 .
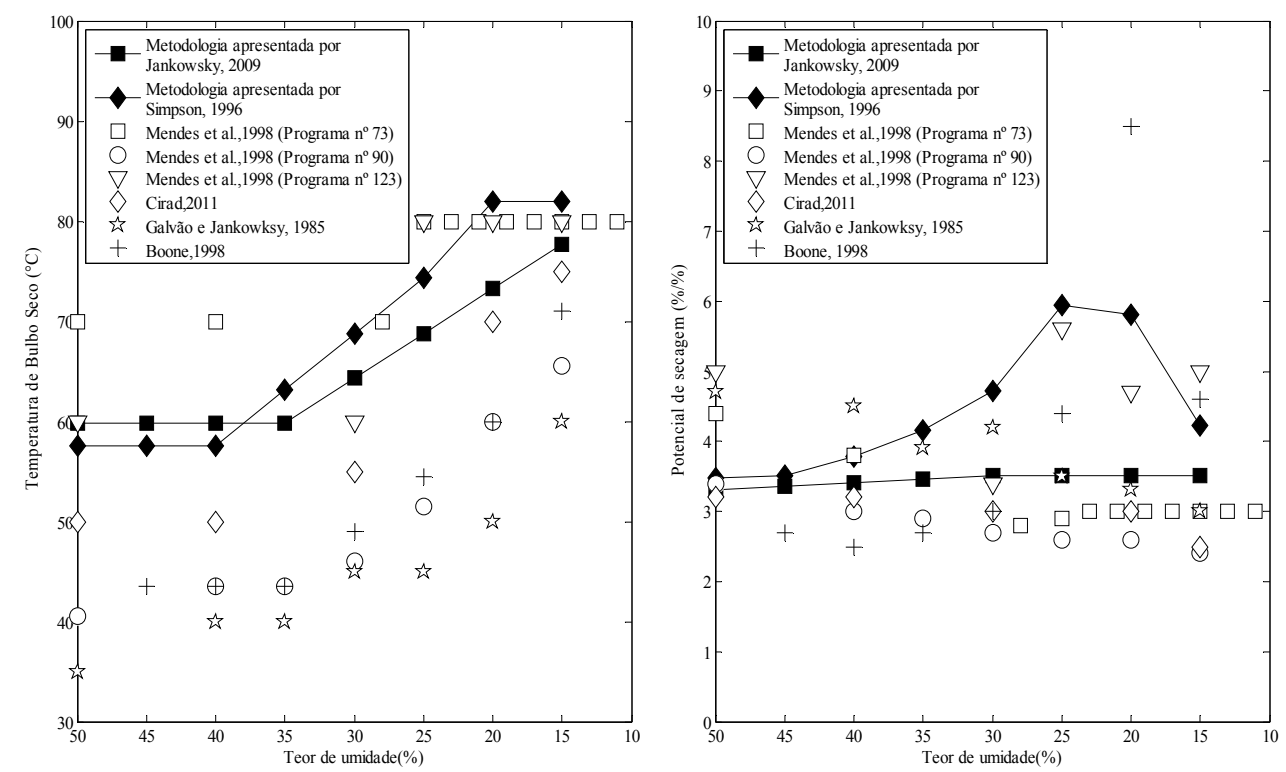

Figura 3. Variação da temperatura de bulbo seco e do potencial de secagem em função da umidade da madeira para virola.

Figure 3. Dry bulb temperature and drying potential variation as a function of virola wood moisture content. 
Da madeira das três espécies avaliadas neste trabalho, a de virola é a que dispõe de maior número de programas de secagem recomendados na literatura. Os programas recomendados por Galvão e Jankowsky (1985), Boone (1988) e o programa 90 apresentado Mendes et al. (1998) apresentam temperaturas iniciais e finais menores. Já os programas recomendados por Cirad (2011) e os programas 73 e 123 apresentados por Mendes et al. (1998) prescrevem temperaturas finais próximas às obtidas neste trabalho (Figura 3).

O programa de secagem propostos por Cirad (2011) e o programa 90 indicado por Mendes et al. (1998) apresentam potenciais de secagem próximos ou inferiores aos calculados neste trabalho. Entretanto, o programa de secagem determinado a partir da secagem drástica foi o que mais se aproximou dos recomendados para madeira de virola. Os programas apresentados por Galvão e Jankowsky (1985), Boone (1988) e o programa 123 recomendado por Mendes et al. (1998) apresentaram como característica potenciais de secagem com uma tendência de decréscimo ao longo do processo.

\section{CONCLUSÕES}

- Em relação à temperatura de bulbo seco, os programas de secagem elaborados para a madeira de marupá e de virola apresentaram diferenças significativas entre os métodos nas fases abaixo do ponto de saturação das fibras; já para o pará-pará, apenas nas fases abaixo desse limite.

- O potencial de secagem apresentou uma tendência comum entre as três espécies, sendo que o método baseado na massa específica básica resulta em valores elevados abaixo do ponto de saturação das fibras.

- Os potenciais de secagem obtidos através da secagem drástica estão mais próximos dos recomendados pela maioria dos autores, para as três espécies analisadas.

- O método da secagem drástica resultou na indicação de programas de secagem compatíveis com aqueles recomendados ou utilizados por outros autores.

\section{REFERÊNCIAS}

ASSOCIAÇÃO BRASILEIRA DA INDÚSTRIA DE MADEIRA PROCESSADA MECANICAMENTE (ABIMCI). Estudo Setorial, ano base 2007. Curitiba - PR: ABIMCI, 2008.

ANDRADE, A. de. Indicação de programas para a secagem convencional de madeiras. 2000. $72 \mathrm{f}$. Dissertação (Mestrado em Ciência e Tecnologia da Madeira) - Escola Superior de Agricultura Luiz de Queiroz, Piracicaba, 2000.

ANDRADE, A. de; JANKOWSKY, I. P.; DUCATTI, M. A. Grupamento de madeiras para secagem convencional. Scientia Forestalis, Piracicaba, n. 59, p. 89 - 99, 2001.

BOONE, R. S.; KOZLIK, C. J.; BOIS, P. J.; WENGERT, E. M. Dry kiln schedules for commercial woods - temperate and tropical. Madison, WI: U.S. Department of Agriculture, Forest Service, Forest Products Laboratory, 1988, 158 p. (Gen. Tech. Rep. FPL-GTR-57).

CENTRE DE COOPERATION INTERNATIONALE EN RECHERCHE AGRONOMIQUE POUR LE DEVELOPPEMENT (CIRAD). Technological characteristics of 245 tropical species. Disponível em: $<$ http://tropix.cirad.fr/america/america.html $>$. Acesso em: 14/06/2011.

DURLO, M. A. Tecnologia da madeira: peso específico. Santa Maria: Centro de Pesquisas Florestais, 1991. 29 p., il. (Série técnica, n. 8).

FEDALTO, L. C.; MENDES, I. da C. A.; CORADIN, V. T. R. Madeiras da Amazônia: Descrição do lenho de 40 espécies ocorrentes na Floresta Nacional do Tapajós. Brasília: IBAMA, 1989. 156 p.

FOREST PRODUCTS LABORATORY. Wood Handbook - Wood as an engineering material. Madison, WI: U. S. Department of Agriculture, Forest Service, Forest Products Laboratory, 1999. (Gen. Tech. Rep. FPL-GTR-113).

GALVÃO, A. P. M.; JANKOWSKY, I. P. Secagem racional da madeira. São Paulo: Nobel, 1985. 111 p. 
INSTITUTO BRASILEIRO DO MEIO AMBIENTE E DOS RECURSOS NATURAIS RENOVÁVEIS (IBAMA). Disponível em: <http://www.ibama.gov.br/lpf/madeira >. Acesso em: 20/10/2011.

INSTITUTO DE PESQUISAS TECNOLÓGICAS DO ESTADO DE SÃO PAULO (IPT). Fichas de Características das Madeiras Brasileiras. 2. ed. São Paulo: IPT, 1989a. 418 p. (publicação IPT $\left.\mathrm{n}^{\circ} 1791\right)$.

JANKOWSKY, I. P. Metodologia simplificada para indicação de programas de secagem. $129 \mathrm{f}$. Tese (Livre-docência em Ciência e Tecnologia da Madeira) - Escola Superior de Agricultura "Luiz de Queiroz", Piracicaba, 2009.

JANKOWSKY, I. P.; LUIZ, M. G. Review of wood drying research in Brazil: 1984-2004. Drying Technology, v. 24, p. 447 - 455, 2006.

MARQUES, M. H. B. (Coord.). Madeiras da Amazônia: características e utilização. Brasília: Instituto Brasileiro do Meio Ambiente e dos Recursos Naturais Renováveis, 1997. 141 p.

MENDES, A. de S.; MARTINS, V. A.; MARQUES, M. H. B. Programas de secagem para madeiras brasileiras. Brasília: Instituto Brasileiro do Meio Ambiente e dos Recursos Naturais Renováveis, 1998. 114 p.

SANTOS, G. R. V. Otimização da secagem da madeira de Eucalyptus grandis [Hill ex Maiden]. 70 p. Dissertação (Mestrado em Ciência e Tecnologia da Madeira) - Escola Superior de Agricultura "Luiz de Queiroz", Piracicaba, 2002.

SIMPSON, W. T. Method to estimate dry-kiln schedules and species groupings: Tropical and temperate hardwoods. Madison, WI: U.S. Department of Agriculture, Forest Service, Forest Products Laboratory. 1996, 57 p. (Resp. Pap. FPL-RP-548).

SIMPSON, W. T.; VERRILL, S. P. Estimating kiln schedules for tropical and temperate hardwoods using specific gravity. Forest Prod. J., v. 47, n. 7/8, 1997, p. 64 - 68. 